Dahu Ding, Yingxin Zhao, Shengjiong Yang, Wansheng Shi, Zhenya Zhang, Zhongfang Lei, Yingnan Yang*

6 Graduate School of Life and Environmental Sciences, University of Tsukuba, Tsukuba, Ibaraki 305-8572, Japan

\section{Adsorption of cesium from aqueous solution using agricultural residue - walnut shell: Equilibrium, kinetic and thermodynamic modeling studies} 7 8

$9_{9}^{*}$ Corresponding author. Graduate School of Life and Environmental Sciences, University of Tsukuba, 1-1-1 ${ }_{10}$ Tennodai, Tsukuba, Ibaraki 305-8572, Japan.

${ }_{11}$ Tel.: +81 29-853-4650; Fax: +81 29-853-4650

${ }_{12}$ E-mail address: yo.innan.fu@u.tsukuba.ac.jp (Y. Yang)

13

14

\section{${ }_{15}$ Abstract}

${ }_{16}$ A novel biosorbent derived from agricultural residue - walnut shell (WS) is reported to remove cesium from aqueous ${ }_{17}$ solution. Nickel hexacyanoferrate (NiHCF) was incorporated into this biosorbent, serving as a high selectivity trap ${ }_{18}$ agent for cesium. Field emission scanning electron microscope (FE-SEM) and thermogravimetric and differential ${ }_{19}$ thermal analysis (TG-DTA) were utilized for the evaluation of the developed biosorbent. Determination of kinetic ${ }_{20}$ parameters for adsorption was carried out using pseudo first-order, pseudo second-order kinetic models and ${ }_{21}$ intra-particle diffusion models. Adsorption equilibrium was examined using Langmuir, Freundlich and ${ }_{22}$ Dubinin-Radushkevich adsorption isotherms. A satisfactory correlation coefficient and relatively low chi-square ${ }_{23}$ analysis parameter $\chi^{2}$ between the experimental and predicted values of the Freundlich isotherm demonstrate that ${ }_{24}$ cesium adsorption by NiHCF-WS is a multilayer chemical adsorption. Thermodynamic studies were conducted under 
${ }_{25}$ different reaction temperatures and results indicate that cesium adsorption by NiHCF-WS is an endothermic $\left(\Delta \mathrm{H}^{\circ}>0\right)$ ${ }_{26}$ and spontaneous $\left(\Delta \mathrm{G}^{\circ}<0\right)$ process.

${ }_{27}$ Keywords: Walnut shell; Nickel hexacyanoferrate (NiHCF); Cesium adsorption; Integrated analysis.

\section{${ }_{28}$ 1. Introduction}

29 Removal of pollutants from industrial wastewater has become one of the most important issues recently for the ${ }_{30}$ increase in industrial activities, especially for heavy metals and radionuclides. Since the big nuclear accident at ${ }_{31}$ Fukushima, Japan in 2011, a large amount of radionuclides were released into water, soil and air, and the hazardous ${ }_{32}$ influence of radioactive wastewater has drawn much attention all over the world. Among radionuclides, ${ }^{137} \mathrm{Cs}$ is ${ }_{33}$ considered the most abundant and hazardous due to diverse sources and relatively long half-life. Furthermore, it can ${ }_{34}$ be easily incorporated into terrestrial and aquatic organisms because of its similar chemical characteristics with ${ }_{35}$ potassium (Nilchi et al. 2011, Plazinski and Rudzinski 2009). As a result, numerous efforts have been undertaken to ${ }_{36}$ find effective and low cost methods to separate and remove cesium (Cs) from waste solutions (Karamanis and ${ }_{37}$ Assimakopoulos 2007, Lin et al. 2001, Nilchi et al. 2011, Parab and Sudersanan 2010, Volchek et al. 2011). ${ }_{38}$ Generally speaking, the investigated physical-chemical methods for separation and removal of Cs are precipitation, з9 solvent extraction, adsorption, ion exchange, electrochemical and membrane processes (Avramenko et al. 2011, Chen ${ }_{40}$ et al. , 2013, Delchet et al. 2012, Duhart et al. 2001, Karamanis and Assimakopoulos 2007, Lin et al. 2001). Among ${ }_{41}$ them, solvent extraction, ion exchange and adsorption methods are most widely used. However, due to the high cost ${ }_{42}$ of materials, large-scale application of solvent extraction is limited. In the case of ion exchange process, inorganic ion ${ }_{43}$ exchangers are found to be superior over organic ion exchangers due to their thermal stability, resistance to ionizing ${ }_{44}$ radiation and good compatibility with final waste forms (Nilchi et al. 2002, Plazinski and Rudzinski 2009). Natural ${ }_{45}$ occurring clay minerals such as zeolite, bentonite and montmorillonite are usually used as low cost adsorption ${ }_{46}$ materials for $\mathrm{Cs}^{+}$removal from aqueous solution, however the main disadvantage is the competitive interactions of ${ }_{47}$ other monovalent cations, in particular $\mathrm{Na}^{+}$and $\mathrm{K}^{+}$that can considerably block $\mathrm{Cs}^{+}$adsorption (Borai et al. 2009, ${ }_{48}$ El-Naggar et al. 2008, Goñi et al. 2006, Lehto 1987, Plazinski and Rudzinski 2009).

49 Transition metal hexacyanoferrates, especially nickel hexacyanoferrate (NiHCF) is known as a highly selective ${ }_{50}$ agent for $\mathrm{Cs}^{+}$adsorption (Chen et al. , 2013, Plazinski and Rudzinski 2009). It possesses a special cubic structure with ${ }_{51}$ a channel diameter of about $3.2 \AA$, through which only small hydrated ions like $\mathrm{Cs}^{+}$can permeate. Larger hydrated 
${ }_{52}$ ions like $\mathrm{Na}^{+}$get blocked (Plazinski and Rudzinski 2009, Pyrasch et al. 2003). However, the very fine particle size of

${ }_{53} \mathrm{NiHCF}$ restricts its direct use in practice, thus proper support materials are necessary.

${ }_{54} \quad$ Recently, several kinds of low cost biosorbents have been investigated for the removal of heavy metals (Figueira ${ }_{55}$ et al. 2000, Plazinski and Rudzinski 2009, Reddad et al. 2002). Walnut shell, an abundant agricultural residue with ${ }_{56}$ good stability has been successfully used in removing heavy metals by adsorption (Altun and Pehlivan 2012, Saadat ${ }_{57}$ and Karimi-Jashni 2011, Zabihi et al. 2010). To the best of our knowledge, however, few studies have focused on ${ }_{58}$ equilibrium, kinetic and thermodynamic modeling of $\mathrm{Cs}^{+}$adsorption using walnut shell. This study presents the first ${ }_{59}$ low cost biosorbent derived from walnut shell (WS) as support material incorporated into NiHCF (NiHCF-WS), ${ }_{60}$ fabricated for $\mathrm{Cs}^{+}$adsorption.

\section{${ }_{61} 2$. Materials and methods}

\section{${ }_{62} 2.1$ Materials}

63 Walnut shell used in this study was obtained from Shandong province, China and was immersed and washed ${ }_{64}$ with pure water to remove soluble impurities until the water turned clear. The clean WS was completely dried in an ${ }_{65}$ oven (EYELA WFO-700, Japan) at $105^{\circ} \mathrm{C}$ for more than 24 hours, ground and sieved through No. 8 and 16 size ${ }_{66}$ meshes. The granules with diameter between $1 \sim 2.36 \mathrm{~mm}$ were selected and stored in a desiccator for further use or ${ }_{67}$ modification.

\section{${ }_{68} 2.2$ Reagents}

69 The chemicals nickel chloride $\left(\mathrm{NiCl}_{2} \bullet 6 \mathrm{H}_{2} \mathrm{O}\right)$ and potassium hexacyanoferrate $\left(\mathrm{K}_{3}\left[\mathrm{Fe}(\mathrm{CN})_{6}\right] \cdot 3 \mathrm{H}_{2} \mathrm{O}\right)$ of A.R. ${ }_{70}$ grade were purchased from Wako Pure Chemical Industries Ltd., Japan. Non-radioactive cesium chloride (CsCl) ${ }_{71}$ purchased from Tokyo Chemical Industry Co. Ltd., Japan was used as a surrogate for ${ }^{137}$ Cs because of its same 72 chemical characteristics. All the other reagents used in this study were purchased from Wako Pure Chemical ${ }_{73}$ Industries Ltd., Japan with no purification before use. Pure water generated from a Millipore Elix 3 water purification ${ }_{74}$ system (Millipore, USA) equipped with a Progard 2 pre-treatment pack was used throughout the experiments except ${ }_{75}$ for ICP-MS analysis.

${ }_{76} \quad 1.26 \mathrm{~g} \mathrm{CsCl}$ was weighed exactly and dissolved into $1 \mathrm{~L}$ pure water as standard stock $\mathrm{Cs}^{+}$solution $\left(1000 \mathrm{mg} \mathrm{L}^{-1}\right)$, 77 which could be diluted to desired concentrations of $\mathrm{Cs}^{+}$solution for further experiments. 


\section{${ }_{78} 2.3$ Modification of walnut shell}

79 The modification of walnut shell contains the following steps. $10 \mathrm{~g}$ of clean WS granules were immersed in 100 ${ }_{80} \mathrm{~mL}$ of $50 \%(\mathrm{v} / \mathrm{v} \%)$ hydrochloric acid $(\mathrm{HCl})$ for 10 hours at a temperature of $50^{\circ} \mathrm{C}$. Then, the WS was dried in an oven ${ }_{81}$ at $105^{\circ} \mathrm{C}$ overnight after being washed until the eluent $\mathrm{pH}$ was almost neutral. The loading of $\mathrm{NiCl}_{2}$ onto WS and the ${ }_{82}$ treatment of $\mathrm{K}_{3}\left[\mathrm{Fe}(\mathrm{CN})_{6}\right] \cdot 3 \mathrm{H}_{2} \mathrm{O}$ with $\mathrm{NiCl}_{2}$ loaded WS was carried out according to the method reported by Parab вз and Sudersanan (Parab and Sudersanan 2010). In brief, $5 \mathrm{~g}$ of WS was immersed in $20 \mathrm{mLof} 0.5 \mathrm{M} \mathrm{NiCl}_{2} \bullet 6 \mathrm{H}_{2} \mathrm{O}$ ${ }_{84}$ solution and placed in a double shaker (Taitec NR-30, Japan) at $200 \mathrm{rpm}$ and room temperature $\left(25 \pm 1^{\circ} \mathrm{C}\right)$ for 24 ${ }_{85}$ hours followed by filtration and washing with pure water to remove excess $\mathrm{NiCl}_{2} \bullet 6 \mathrm{H}_{2} \mathrm{O}$. Next, the $\mathrm{NiCl}_{2}$ loaded WS ${ }_{86}$ was added to $10 \mathrm{~mL}$ of $5 \%(\mathrm{wt} \%) \mathrm{K}_{3}\left[\mathrm{Fe}(\mathrm{CN})_{6}\right] \cdot 3 \mathrm{H}_{2} \mathrm{O}$ solution and placed into a water bath (SANSYO SWR-281D, ${ }_{87}$ Japan) at $30^{\circ} \mathrm{C}$ for 24 hours. The resultant NiHCF loaded WS was separated by filtration, washed with pure water ${ }_{88}$ and dried at $60^{\circ} \mathrm{C}$. The entire procedure was repeated three times to ensure the incorporation of NiHCF onto the WS. ${ }_{89}$ This NiHCF-WS material was used for further characterization as well as $\mathrm{Cs}^{+}$adsorption studies.

\section{${ }_{90} 2.4$ Kinetic studies}

${ }_{91} \quad 4 \mathrm{~g}$ of NiHCF-WS was mixed with $200 \mathrm{~mL} \mathrm{Cs}^{+}$solution (adsorbent dosage of $20 \mathrm{~g} \mathrm{~L}^{-1}$ ) in a $200 \mathrm{~mL}$-glass flask ${ }_{92}$ (AS ONE, Japan) under initial $\mathrm{Cs}^{+}$concentration of $10 \mathrm{mg} \mathrm{L}^{-1}$, and the flask was shaken by a double shaker (TAITEC ${ }_{93}$ NR-30, Japan) at 200 rpm for 48 hours. Supernatants (about $1 \mathrm{~mL}$ for each) including the initial solution (as the zero ${ }_{94}$ min point) were withdrawn at predetermined time intervals prior to the $\mathrm{Cs}^{+}$concentration determination.

95 In order to investigate the mechanism of adsorption, non-linearized Lagergren pseudo first-order kinetic model ${ }_{96}$ (Karamanis and Assimakopoulos 2007) and pseudo second-order kinetic model (Parab and Sudersanan 2010) were ${ }_{97}$ applied to analyze the adsorption process, which were expressed as follows: Lagergren pseudo first-order kinetic model:

99

pseudo second-order kinetic model:

$$
q_{t}=\frac{k_{2} q_{e}{ }^{2} t}{1+k_{2} q_{e} t}
$$


102 where $t$ (min) is the contact time, $k_{1}\left(\mathrm{~min}^{-1}\right)$ and $k_{2}\left(\mathrm{~g} \mathrm{mg}^{-1} \mathrm{~min}^{-1}\right)$ are the adsorption rate constants; $q_{e}$ and $q_{t}\left(\mathrm{mg} \mathrm{g}^{-1}\right)$ ${ }_{103}$ represent the uptake amount of ion by the adsorbent at equilibrium and time $t$, respectively.

${ }_{104}$ In addition, the determination of the limiting step of the adsorption process is necessary by predicting the ${ }_{105}$ diffusion coefficient using a diffusion based model. The possibility of intra-particle diffusion resistance affecting the 106 adsorption was explored in this study by using the intra-particle diffusion equation (Delchet et al. 2012) as follows:

$q_{t}=k_{p} t^{1 / 2}+C$

108 where $t(\mathrm{~min})$ is the contact time, $q_{t}\left(\mathrm{mg} \mathrm{g}^{-1}\right)$ is the $\mathrm{Cs}^{+}$uptake amount at time $t, k_{p}\left(\mathrm{mg} \mathrm{g}^{-1} \mathrm{~min}^{-1 / 2}\right)$ is the intra-particle ${ }_{109}$ diffusion rate constant determined from the slopes of the linear plots. $C$ is the constant, which indicates the thickness ${ }_{110}$ of the boundary layer, i.e., the larger the value of $C$ the greater is the boundary layer effect.

\subsection{Equilibrium studies}

${ }_{112}$ A fixed amount of NiHCF-WS was mixed with $20 \mathrm{~mL} \mathrm{Cs}^{+}$solution in a 50mL-polypropylene tube (VIOLAMO, ${ }_{113}$ Japan) at a shaking speed of 200rpm. Resultant supernatants were withdrawn after 24 hours prior to the Cs ${ }^{+}$ 114 concentration determination.

\section{2.5.1 Adsorption isotherms}

116 To optimize the design of a adsorption system, it is important to establish the most appropriate correlation for ${ }_{117}$ equilibrium conditions (Parab and Sudersanan 2010). According to different adsorption mechanisms, there are ${ }_{118}$ currently several different adsorption isotherms used for fitting experimental adsorption results. Among these, ${ }_{119}$ Langmuir (Langmuir 1918), Freundlich (Freundlich 1907) and Dubinin-Radushkevich (D-R) (Dubinin et al. 1947) 120 isotherms are widely used and therefore are applied in this study. The nonlinear forms of these isotherms are given as ${ }_{121}$ follows:

122

123

124
Langmuir isotherm: $q_{e}=\frac{q_{m} b C_{e}}{1+b C_{e}}$

Freundlich isotherm: $q_{e}=k_{f} C_{e}^{n}$

D-R isotherm: $q_{e}=q_{m} \exp \left(-\beta \varepsilon^{2}\right)$ 


$$
{ }^{125} \quad \varepsilon=R T \ln \left(1+\frac{1}{C_{e}}\right)
$$

126 where, $q_{e}\left(\mathrm{mg} \mathrm{g}^{-1}\right)$ is the amount of $\mathrm{Cs}^{+}$adsorbed at equilibrium, $C_{e}\left(\mathrm{mg} \mathrm{L}^{-1}\right)$ is the equilibrium concentration of $\mathrm{Cs}^{+} . b$

${ }_{127}\left(\mathrm{~L} \mathrm{mg}^{-1}\right)$ is a constant related to the free energy or net enthalpy of adsorption $\left(b \propto e^{-\Delta G / R T}\right)$ (Mohan and Singh 2002), ${ }_{128}$ and $q_{m}\left(\mathrm{mg} \mathrm{g}^{-1}\right)$ is the adsorption capacity at the isotherm temperature. $k_{f}$ and $n$ are equilibrium constants indicative of 129 adsorption capacity and adsorption intensity respectively. $\beta\left(\mathrm{mol}^{2} / \mathrm{kJ}^{2}\right)$ is the constant related to the adsorption energy, ${ }_{130} R\left(8.314 \mathrm{~J} \mathrm{~mol}^{-1} \mathrm{~K}^{-1}\right)$ is the gas constant and $T(\mathrm{~K})$ is the absolute temperature of the aqueous solution.

\section{${ }_{131}$ 2.5.2 Role of ion exchange}

${ }_{132}$ In the case of anionic metal hexacyanoferrate complexes, it is assumed that there is a true exchange between $\mathrm{K}^{+}$ 133 and $\mathrm{Cs}^{+}$(Haas 1993, Lehto 1987). Therefore, an attempt was made to link the $\mathrm{Cs}^{+}$adsorption to its likely ion ${ }_{134}$ exchange reaction with $\mathrm{K}^{+}$through equilibrium studies. In addition to the batch experiments, a blank experiment was ${ }_{135}$ carried out by adding a corresponding amount of adsorbent into the same volume of pure water instead of $\mathrm{Cs}^{+}$ ${ }_{136}$ solutions. The $\mathrm{Cs}^{+}$adsorbed and $\mathrm{K}^{+}$released was calculated according to mass balance using the equations below:

$$
{ }_{137} A_{\mathrm{Cs}^{+}}=\frac{\left(C_{0}-C_{e}\right) V}{133} \times 1000
$$

${ }_{138}$ where $A_{\mathrm{Cs}^{+}}(\mu \mathrm{mol})$ is the amount of $\mathrm{Cs}^{+}$adsorbed by NiHCF-WS, $C_{0}\left(\mathrm{mg} \mathrm{L}^{-1}\right)$ is the initial concentration of $\mathrm{Cs}^{+}, C_{e}$ $139\left(\mathrm{mg} \mathrm{L}^{-1}\right)$ is the equilibrium concentration of $\mathrm{Cs}^{+}, V(\mathrm{~L})$ is the volume of solution and 133 is the molar mass of Cs.

$$
R_{K^{+}}=\frac{\left(C_{e}-C_{b}\right) V}{39} \times 1000
$$

${ }_{141}$ where $R_{K^{+}}(\mu \mathrm{mol})$ is the amount of $\mathrm{K}^{+}$released into solution, $C_{e}\left(\mathrm{mg} \mathrm{L}^{-1}\right)$ is the equilibrium concentration of $\mathrm{K}^{+}, C_{b}$ ${ }_{142}\left(\mathrm{mg} \mathrm{L}^{-1}\right)$ is the concentration of $\mathrm{K}^{+}$in the blank solution, $V(\mathrm{~L})$ is the volume of solution and 39 is the molar mass of ${ }_{143} \mathrm{~K}$.

\section{${ }_{144}$ 2.6 Thermodynamic studies}

145 In order to obtain the thermodynamic nature of the adsorption process, $0.2 \mathrm{~g}$ NiHCF-WS was added into $20 \mathrm{~mL}$ ${ }_{146} \mathrm{Cs}^{+}$solutions with an initial concentration of $10 \mathrm{mg} \mathrm{L}^{-1}$ (adsorbent dosage of $10 \mathrm{~g} \mathrm{~L}^{-1}$ ) at different temperatures (298, ${ }_{147} 308$ and 318K) for 24h. Thermodynamic parameters, namely, standard Gibbs free energy $\left(\Delta \mathrm{G}^{\circ}\right)$, standard enthalpy ${ }_{148}\left(\Delta \mathrm{H}^{\circ}\right)$ and standard entropy $\left(\Delta \mathrm{S}^{\circ}\right)$ changes were also determined in order to obtain the thermodynamic nature of the 
${ }_{149}$ adsorption process. The amounts of $\Delta \mathrm{H}^{\circ}$ and $\Delta \mathrm{S}^{\circ}$ could be calculated from the slope and intercept of the straight line ${ }_{150}$ obtained from plotting $\operatorname{lnKd}$ versus 1/T, respectively using the following equation (Nilchi et al. 2011, Tsai et al. 151 2009):

$$
{ }_{152} \ln K d=\frac{\Delta S^{\circ}}{R}-\frac{\Delta H^{\circ}}{R T}
$$

${ }_{153}$ where $K d\left(\mathrm{~mL} \mathrm{~g}^{-1}\right)$ is the distribution coefficient, $R\left(8.314 \mathrm{~J} \mathrm{~mol}^{-1} \mathrm{~K}^{-1}\right)$ is the gas constant and $T(\mathrm{~K})$ is the absolute 154 temperature of the aqueous solution.

155 After obtaining $\Delta \mathrm{H}^{\circ}$ and $\Delta \mathrm{S}^{\circ}$ values of the adsorption, $\Delta \mathrm{G}^{\circ}$ of each temperature was calculated by the 156 well-known equation as follows:

$$
\Delta G^{\circ}=\Delta H^{\circ}-T \Delta S^{\circ}
$$

\section{2.7 Analysis}

${ }_{159}$ All of the samples were collected by filtering supernatants through $0.22 \mu \mathrm{m}$ mixed cellulose ester membrane 160 (Millipore, Ireland) and diluted with pure water to a proper extent (below $1 \mathrm{mg} \mathrm{L}^{-1}$ ) into $15 \mathrm{~mL}$-polypropylene tubes ${ }_{161}$ (VIOLAMO, Japan) prior to inductively coupled plasma-mass spectrometry (ICP-MS) (Perkin Elmer ELAN DRC-e, ${ }_{162}$ USA) analysis.

${ }_{163}$ In order to evaluate the probable differences in structure between raw and modified walnut shell, field emission ${ }_{164}$ Scanning electron microscope (FE-SEM) analysis was performed using a JEOL JSM-6330F type microscope. A ${ }_{165}$ thermogravimetric and differential thermal analysis (TG-DTA) of WS and NiHCF-WS was carried out using a ${ }_{166}$ thermal analyzer (EXSTAR TG/DTA 7300, Japan) equipped with an AS-3 auto sampler. About 7.5mg of each ${ }_{167}$ sample was prepared into an aluminum-PAN, heated up to $500^{\circ} \mathrm{C}$ at a constant rate of $10^{\circ} \mathrm{C} \mathrm{min}^{-1}$ in normal 168 atmosphere for thermal analysis using an open-Al-pan as reference. The whole procedure is shown in Fig.S1 (see ${ }_{169}$ Electronic Supplementary Material) during which the air flow rate was kept at 200mL $\mathrm{min}^{-1}$.

170 The concentrations of $\mathrm{Cs}^{+}$and $\mathrm{K}^{+}$in aqueous samples were analyzed by a fully quantitative analytical method on ${ }_{171}$ a Perkin Elmer ELAN DRC-e ICP-MS in standard mode. Each sample was analyzed 5 times and the average was ${ }_{172}$ taken. The relative standard deviation (RSD) of multiple measurements was less than $2 \%$ and in most cases, less than $1731.5 \%$. 


\subsection{Calculation}

${ }_{175}$ The $\mathrm{Cs}^{+}$adsorption results are given as uptake amount $(q)$ and distribution coefficient $(K d)$. The $\mathrm{Cs}^{+}$uptake 176 amount $q\left(\mathrm{mg} \mathrm{g}^{-1}\right)$ was calculated from the mass balance as follows:

$$
{ }_{177} \quad q=\frac{\left(C_{0}-C_{t}\right) V}{1000 M}
$$

178 Distribution coefficient $K d\left(\mathrm{~mL} \mathrm{~g}^{-1}\right)$, which is mass-weighted partition coefficient between solid phase and liquid ${ }_{179}$ supernatant phase reflecting the selectivity for objective metal ions, was calculated according to the formula:

$$
{ }_{180} \quad K d=\frac{C_{0}-C_{t}}{C_{t}} \times \frac{V}{M}
$$

${ }_{181}$ where, $C_{0}$ and $C_{t}\left(\mathrm{mg} \mathrm{L}^{-1}\right)$ are the concentrations of $\mathrm{Cs}^{+}$at contact time of 0 (initial concentration) and $t$ determined 182 by ICP-MS, $V(\mathrm{~mL})$ is the volume of $\mathrm{Cs}^{+}$solution and $M(\mathrm{~g})$ is the mass of adsorbent used.

\section{${ }_{183} 2.9$ Quality assurance and quality control}

${ }_{184}$ In order to ensure reliability and improve accuracy of the experimental data in this study, kinetic and equilibrium 185 studies on $\mathrm{Cs}^{+}$adsorption were conducted in duplicate with a mean $\pm \mathrm{SD}$ being reported. All of the figures and the ${ }_{186}$ kinetic fitting displayed in this paper were accomplished using the Origin 7.5 program (OriginLab, USA).

\section{3. Results and discussion}

\section{3.1 Characterization of biosorbent}

\section{3.1.1 Field emission scanning electron microscope (FE-SEM)}

190 The FE-SEM images of walnut shell before and after modification are shown in Fig.1. It can be seen that the raw 191 walnut shell has a complex and multilayer structure including the obvious fibrous lignocellulosic (Fig.1a). After 192 modification, there is a remarkable difference in the surface structure of walnut shell with NiHCF particles attached ${ }_{193}$ on the surface of walnut shell, as depicted by the arrows in Fig.1b.

\section{${ }_{194}$ 3.1.2 Thermogravimetric and differential thermal analysis (TG-DTA)}

195 A large number of reactions occur during the thermal degradation of lignocellulosic materials. Therefore, a 196 thermal degradation pre-study conducted on the biomass material, is very important in terms of the efficient design of 
197 thermochemical processes for the conversion of biomass into energy and products (Damartzis et al. 2011). The ${ }_{198}$ TG-DTA curves, which display the thermal degradation characteristics for the WS and NiHCF-WS, were recorded as 199 a function of time (Fig.2). Based on the TG curves, it can be said that the major mass loss occurred in the thermal 200 degradation of WS (98.2\%) and NiHCF-WS (96.4\%), respectively. Their TG curves can be divided into three parts; ${ }_{201}$ representing loss of water, volatilation of hemicellulose like contents, and decomposition of celloluse and lignin ${ }_{202}$ components (Kar 2011). Compared with WS, the second and last parts of the TG curves obtained from the ${ }_{203} \mathrm{NiHCF}-W \mathrm{~S}$ were obviously different with shorter time needed. It can be seen that approximately $37.4 \%$ of TG loss ${ }_{204}$ Occurred during the second part and finished at a time of about 28 minute for the NiHCF-WS. However, the positive ${ }_{205}$ peak of the DTA curve was more obvious than that of WS, which might be due to the loss of impurities with lower ${ }_{206}$ calorific value than hemicellulose during the modification. Another great difference, the third part began at time of 30 ${ }_{207}$ minutes and temperature of about $350^{\circ} \mathrm{C}$, much lower than WS, indicating the decomposition temperature greatly ${ }_{208}$ decreased after modification. During this step, approximately 52.3\% of TG was lost, higher than that of WS.

${ }_{209}$ Through comparing the TG-DTA results of WS and NiHCF-WS, it can be concluded that the modification ${ }_{210}$ process didn't alter the thermal stability of WS and therefore NiHCF-WS can be used as a thermally stable adsorbent.

\section{${ }_{211} 3.2$ Effect of contact time and kinetic study}

${ }_{212}$ Fig.3 shows the effect of contact time on the $\mathrm{Cs}^{+}$adsorption and application of kinetic models to $\mathrm{Cs}^{+}$adsorption ${ }_{213}$ by WS and NiHCF-WS. Table 1 lists the sorption rate constants associated with pseudo first and second order kinetic ${ }_{214}$ models. It can be seen from Fig. 3 that $\mathrm{Cs}^{+}$adsorption is a rapid process, about $2 \mathrm{~h}$ is needed to reach equilibrium for 215 the NiHCF-WS. The equilibrium uptake amount of $\mathrm{Cs}^{+}$was greater than $0.5 \mathrm{mg} \mathrm{g}^{-1}$. In addition, the adsorption ${ }_{216}$ process on only-WS is complicated and not efficient with an equilibrium uptake amount of approximately $0.1 \mathrm{mg} \mathrm{g}^{-1}$. ${ }_{217}$ It is clearly indicated that the NiHCF-WS has a much better adsorption performance for $\mathrm{Cs}^{+}$than only-WS.

218 Compared to the first-order model, the pseudo second-order kinetic model had a higher correlation coefficient ${ }_{219}$ for NiHCF-WS, suggesting that the $\mathrm{Cs}^{+}$adsorption process is a chemisorption rather than physisorption.

220 Fig.4 shows the amount of adsorbed $\mathrm{Cs}^{+}, q_{t}\left(\mathrm{mg} \mathrm{g}^{-1}\right)$, versus the square root of time for NiHCF-WS. The ${ }_{221}$ presence of three linear regions on the curve is possibly due to the presence of three steps during the adsorption ${ }_{222}$ process (Damartzis et al. 2011): an external mass transfer step such as the boundary layer diffusion occurred first, ${ }_{223}$ then an intra-particle diffusion step for the second and lastly a saturation step. In this study, the first linear region with 
224 a high slope signaled a rapid external diffusion stage depicting macro-pore or inter-particle diffusion, which is ${ }_{225}$ different from the second step, gradual adsorption stage controlled by intra-particle (micro-pore) diffusion, and the 226 last step (saturation stage). This observation can also be linked with adsorption mechanisms mainly involving the 227 surface layers of crystallites (Ramaswamy 1999).

\subsection{Equilibrium studies}

\section{3.3.1 Cesium adsorption isotherms}

230 In order to obtain the equilibrium isotherm, the initial $\mathrm{Cs}^{+}$concentration varied from 5-400 $\mathrm{mg} \mathrm{L}^{-1}(5,10,20,50$, $23175,100,200,400$ ) while maintaining an adsorbent dosage of $20 \mathrm{~g} \mathrm{~L}^{-1}$, and the amount of adsorbed $\mathrm{Cs}^{+}$was 232 investigated.

${ }_{233}$ Fig.5 shows the application of nonlinear Langmuir, Freundlich and D-R isotherms to the $\mathrm{Cs}^{+}{ }$adsorption on ${ }_{234}$ NiHCF-WS. In this study, chi-square analysis was applied to estimate the degree of difference $\left(\chi^{2}\right)$ between the ${ }_{235}$ experimental data and the isotherm data, which is calculated by the following equation (Mirmohseni et al. 2012):

$$
{ }^{236} \chi^{2}=\sum \frac{\left(q_{e}{ }^{\text {exp }}-q_{e}{ }^{c a l}\right)^{2}}{q_{e}{ }^{c a l}}
$$

${ }_{237}$ where $q_{e}^{\text {cal }}\left(\mathrm{mg} \mathrm{g}^{-1}\right)$ is the equilibrium uptake amount calculated from the isotherm and $q_{e} e^{\text {exp }}\left(\mathrm{mg} \mathrm{g}^{-1}\right)$ is the ${ }_{238}$ experimental equilibrium uptake amount. A smaller $\chi^{2}$ value indicates a better fitting isotherm.

${ }_{239}$ In addition, the values of normalized standard deviation (NSD (\%)) were also calculated to validate the fitness of 240 isotherm to experimental data (Karamanis and Assimakopoulos 2007), which is defined as:

$$
\mathrm{NSD}(\%)=100 \times \sqrt{\frac{\sum\left[\left(q_{e}{ }^{\mathrm{exp}}-q_{e}{ }^{c a l}\right) / q_{e}{ }^{\exp }\right]^{2}}{N-1}}
$$

${ }_{242}$ where $N$ is the number of measurements. Similarly, a smaller NSD (\%) value indicates a better fitting isotherm.

${ }^{243}$ The results of $\chi^{2}$ and NSD (\%) are given in Table 2 and indicate the three adsorption isotherms match the ${ }_{244}$ experimental data $\left(\mathrm{R}^{2}>0.9\right)$. Although the $\mathrm{R}^{2}$ value of the Freundlich isotherm is similar with that of the Langmuir or ${ }_{245} \mathrm{D}-\mathrm{R}$ isotherm, the $\chi^{2}$ and NSD (\%) values of the Freundlich isotherm are much smaller, implying that the adsorption ${ }_{246}$ of Cs $^{+}$on NiHCF-WS is a multilayer adsorption rather than monolayer adsorption. Furthermore, the value of $n$ is less ${ }_{247}$ than 1, suggesting this adsorption process is favorable (Parab and Sudersanan 2010). 
As another important function, the Langmuir isotherm could give us the estimated maximum adsorption capacity ${ }_{249}\left(q_{m}\right)$ of NiHCF-WS, $4.94 \pm 0.5 \mathrm{mg} \mathrm{g}^{-1}$, which is similar to that provided by D-R isotherm. In conclusion, the adsorption ${ }_{250}$ isotherms demonstrated that the $\mathrm{Cs}^{+}$adsorption onto NiHCF-WS is a multilayer chemical ion exchange process.

\section{3.3.2 Role of ion exchange with $\mathrm{K}^{+}$}

${ }_{252}$ It is hypothesized that if adsorption is mainly caused by ion exchange reaction, then the quantity of the released ${ }_{253}$ cations (in gram-equivalent) would be close to that of the adsorbed target ions. Table 3 shows the relationship ${ }_{254}$ between the $\mathrm{Cs}^{+}$adsorbed and $\mathrm{K}^{+}$released during the $\mathrm{Cs}^{+}$adsorption process and two significant phenomena are ${ }_{255}$ observed. With the increase in dosage (No.1-4) and initial $\mathrm{Cs}^{+}$concentration (No.4-7), both $\mathrm{Cs}^{+}$adsorbed and $\mathrm{K}^{+}$ ${ }_{256}$ released increase, demonstrating affinity between them. On the other hand, the test results reveal that the amount of ${ }_{257} \mathrm{~K}^{+}$released into solutions are greater than that of $\mathrm{Cs}^{+}$adsorbed except for the dosage of $5 \mathrm{~g} \mathrm{~L}^{-1}$ (probably caused by ${ }_{258}$ experimental error). In other words, the released $\mathrm{K}^{+}$from the adsorbent is not completely exchanged by $\mathrm{Cs}^{+}$ ${ }_{259}$ (Avramenko et al. 2011, Loos-Neskovic et al. 2004), which is also in agreement with the relationship between $\mathrm{Ca}^{2+}$ ${ }_{260}$ released and $\mathrm{Cs}^{+}$adsorbed reported by Miah (Miah et al. 2010). This indicates that the amount of $\mathrm{K}^{+}$released into the ${ }_{261}$ solution is partly through dissolution other than ion exchange with $\mathrm{Cs}^{+}$. However, it is not clearly demonstrated the ${ }_{262}$ existence of chemical ion exchange process between $\mathrm{Cs}^{+}$and $\mathrm{K}^{+}$from the data reported in this table. Basing on the ${ }_{263}$ above conclusion that the existence of dissolution of $\mathrm{K}^{+}$, as a result, the variations between adsorbed $\mathrm{Cs}^{+}$and released ${ }_{264} \mathrm{~K}^{+}$at the same dosage $\left(20 \mathrm{~g} \mathrm{~L}^{-1}\right)$ and different initial $\mathrm{Cs}^{+}$concentrations are compared in order to determine the ${ }_{265}$ possible equal relationship between them. As a comparison between No.4 and 5, the variation of adsorbed $\mathrm{Cs}^{+}$is ${ }_{266} 8.94 \pm 0.07 \mu \mathrm{mol}$, which is similar with the variation of released $\mathrm{K}^{+}(8.72 \pm 0.03 \mu \mathrm{mol})$. In addition, the variation of ${ }_{267}$ adsorbed $\mathrm{Cs}^{+}$between No.5 and 6 is $2.01 \pm 0.08 \mu \mathrm{mol}$, which is also similar with the variation of released $\mathrm{K}^{+}$ ${ }_{268}(3.31 \pm 0.17 \mu \mathrm{mol})$. When the initial $\mathrm{Cs}^{+}$concentration is increased from 200 to $400 \mathrm{mg} \mathrm{L}^{-1}$ (No.6 and 7), the variation ${ }_{269}$ of adsorbed $\mathrm{Cs}^{+}(2.21 \pm 0.11 \mu \mathrm{mol})$ is similar with released $\mathrm{K}^{+}(2.91 \pm 0.09 \mu \mathrm{mol})$. Through the above comparisons, it is ${ }_{270}$ consequently concluded that there is indeed an exchange process between $\mathrm{Cs}^{+}$and $\mathrm{K}^{+}$. The $\mathrm{K}^{+}$in the NiHCF-WS ${ }_{271}$ plays an important role in the $\mathrm{Cs}^{+}$adsorption process as the ion exchanger.

\section{3.4 Thermodynamic study}

273 The distribution coefficient $K d$ was calculated using Eq. (13). The plotting of $\ln K d$ versus $1 / T$ gave a straight 274 line with a correlation coefficient $\left(\mathrm{R}^{2}\right)$ of 0.99 (see Fig.S2 in Electronic Supplementary Material), from which the ${ }_{275} \Delta \mathrm{H}^{\circ}$ and $\Delta \mathrm{S}^{\circ}$ was determined using Eq. (10). Furthermore, the standard Gibbs free energy at each temperature was 
${ }_{276}$ calculated using Eq. (11) and the results are listed in Table 4.

277 As shown in Table 4, the distribution coefficient of $\mathrm{Cs}^{+}$adsorption by NiHCF-WS increased remarkably with the 278 increase in temperature, implying that high temperature was favorable for $\mathrm{Cs}^{+}$adsorption. The same phenomenon was 279 observed by Nilchi et al. (Nilchi et al. 2011), who used copper hexacyanoferrate to adsorb $\mathrm{Cs}^{+}$from aqueous solution. ${ }_{280}$ The negative amounts of $\Delta \mathrm{G}^{\circ}$ at different temperatures and the positive amount of $\Delta \mathrm{H}^{\circ}$ revealed that the chemical ion ${ }_{281}$ exchange process was a spontaneous and endothermic adsorption reaction in this study.

\section{4. Conclusion}

${ }_{283}$ Walnut shell, an agricultural residue, was reused as a support material for effective cesium adsorption from ${ }_{284}$ aqueous solution and the integrated analysis of adsorption of cesium from aqueous solution using NiHCF-WS was 285 carried out. The rapid adsorption process fitted well with the pseudo second-order kinetic model with the equilibrium ${ }_{286}$ cesium uptake amount above $0.5 \mathrm{mg} \mathrm{g}^{-1}$. The good correlation coefficient (0.93), low $\chi^{2}$ and NSD values suggest that ${ }_{287}$ cesium adsorption on NiHCF-WS could be best described by the Freundlich adsorption isotherm. Results showed that ${ }_{288}$ the NiHCF-WS was an effective adsorbent for cesium adsorption and the adsorption process was endothermic and 289 Spontaneous. In addition, the incorporation of walnut shell and NiHCF overcame the difficulty of separation of ${ }_{290}$ NiHCF nano-particles from solution. Basing on the conclusions in this study, more effective modification will be ${ }_{291}$ carried out to improve the performance of this material and thereafter the evaluation will be performed for the 292 application of this material into treating real radioactive wastewater in future studies.

\section{${ }_{29}$ Acknowledgements}

294 This work was supported in part by Scientific Research (A) 22248075 from the Japan Society for the Promotion ${ }_{295}$ of Science (JSPS). The authors also want to give thanks to the Environmental Diplomatic Leader (EDL) writing 296 center, University of Tsukuba, for proofreading.

\section{${ }_{297}$ References}

${ }_{298}$ Altun, T. and Pehlivan, E. (2012) Removal of Cr(VI) from aqueous solutions by modified walnut shells. Food $299 \quad$ Chemistry 132(2), 693-700. 
300 Avramenko, V., Bratskaya, S., Zheleznov, V., Sheveleva, I., Voitenko, O. and Sergienko, V. (2011) Colloid stable

301 sorbents for cesium removal: Preparation and application of latex particles functionalized with transition 302 metals ferrocyanides. Journal of Hazardous materials 186(2-3), 1343-1350.

303 Borai, E.H., Harjula, R., malinen, L. and Paajanen, A. (2009) Efficient removal of cesium from low-level radioactive $304 \quad$ liquid waste using natural and impregnated zeolite minerals. Journal of Hazardous materials 172(1), 416-422. ${ }_{305}$ Chen, R., Tanaka, H., Kawamoto, T., Asai, M., Fukushima, C., Na, H., Kurihara, M., Watanabe, M., Arisaka, M. and 306 Nankawa, T. (2013) Selective removal of cesium ions from wastewater using copper hexacyanoferrate 307 nanofilms in an electrochemical system. Electrochimica Acta 87(0), 119-125.

${ }_{308}$ Damartzis, T., Vamvuka, D., Sfakiotakis, S. and Zabaniotou, A. (2011) Thermal degradation studies and kinetic 309 modeling of cardoon (Cynara cardunculus) pyrolysis using thermogravimetric analysis (TGA). Bioresource $310 \quad$ Technology 102(10), 6230-6238.

${ }_{311}$ Delchet, C., Tokarev, A., Dumail, X., Toquer, G., Barre, Y., Guari, Y., Guerin, C., Larionova, J. and Grandjean, A. 312 (2012) Extraction of radioactive cesium using innovative functionalized porous materials. RSC Advances 2(13), 5707-5716.

${ }_{314}$ Dubinin, M.M., Zaverina, E.D. and Radushkevich, L.V. (1947) Sorption and structure of active carbons. I. $315 \quad$ Adsorption of organic vapors. Zh Fiz Khim 21, 1351-1362.

316 Duhart, A., Dozol, J.F., Rouquette, H. and Deratani, A. (2001) Selective removal of cesium from model nuclear w17 waste solutions using a solid membrane composed of an unsymmetrical calix[4]arenebiscrown-6 bonded to an immobilized polysiloxane backbone. Journal of Membrane Science 185(2), 145-155.

${ }_{319}$ El-Naggar, M.R., El-Kamash, A.M., El-Dessouky, M.I. and Ghonaim, A.K. (2008) Two-step method for preparation 320 of NaA-X zeolite blend from fly ash for removal of cesium ions. Journal of Hazardous materials 154(1-3), 321 963-972.

${ }_{322}$ Figueira, M.M., Volesky, B., Azarian, K. and Ciminelli, V.S.T. (2000) Biosorption Column Performance with a 323 Metal Mixture. Environmental Science \& Technology 34(20), 4320-4326.

324 Freundlich, H. (1907) Über die adsorption in lösungen. Journal of Physical Chemistry 57, 385-470.

${ }_{325}$ Goñi, S., Guerrero, A. and Lorenzo, M.P. (2006) Efficiency of fly ash belite cement and zeolite matrices for 326 immobilizing cesium. Journal of Hazardous materials 137(3), 1608-1617. 
${ }_{327}$ Haas, P.A. (1993) A Review of Information on Ferrocyanide Solids for Removal of Cesium from Solutions.

$328 \quad$ Separation Science and Technology 28(17-18), 2479-2506.

${ }_{329}$ Kar, Y. (2011) Co-pyrolysis of walnut shell and tar sand in a fixed-bed reactor. Bioresource Technology 102(20),

330 9800-9805.

${ }_{331}$ Karamanis, D. and Assimakopoulos, P.A. (2007) Efficiency of aluminum-pillared montmorillonite on the removal of 332 cesium and copper from aqueous solutions. Water Research 41(9), 1897-1906.

333 Langmuir, I. (1918) The adsorption of gases on plane surfaces of glass, mica and platinum. Journal of the American ${ }_{334} \quad$ Chemists’ Society 40, 1361-1403.

335 Lehto, J., Harjula, R. (1987) Separation of cesium from nuclear waste solutions with hexacyanoferrate (II)s and $336 \quad$ ammonium phosphomolybdate. Solvent Extraction and Ion Exchange 5, 343-352.

${ }_{337}$ Lin, Y., Fryxell, G.E., Wu, H. and Engelhard, M. (2001) Selective Sorption of Cesium Using Self-Assembled $338 \quad$ Monolayers on Mesoporous Supports. Environmental Science \& Technology 35(19), 3962-3966.

${ }_{339}$ Loos-Neskovic, C., Ayrault, S., Badillo, V., Jimenez, B., Garnier, E., Fedoroff, M., Jones, D.J. and Merinov, B. (2004) Structure of copper-potassium hexacyanoferrate (II) and sorption mechanisms of cesium. Journal of Solid State Chemistry 177(6), 1817-1828.

${ }_{342}$ Miah, M.Y., Volchek, K., Kuang, W. and Tezel, F.H. (2010) Kinetic and equilibrium studies of cesium adsorption on ceiling tiles from aqueous solutions. Journal of Hazardous materials 183(1-3), 712-717.

${ }_{344}$ Mirmohseni, A., Seyed Dorraji, M.S., Figoli, A. and Tasselli, F. (2012) Chitosan hollow fibers as effective biosorbent toward dye: Preparation and modeling. Bioresource Technology 121(0), 212-220.

${ }_{346}$ Mohan, D. and Singh, K.P. (2002) Single- and multi-component adsorption of cadmium and zinc using activated 347 carbon derived from bagasse — an agricultural waste. Water Research 36(9), 2304-2318.

${ }_{348}$ Nilchi, A., Khanchi, A. and Ghanadi Maragheh, M. (2002) The importance of cerium substituted phosphates as cation 349 exchanger—some unique properties and related application potentials. Talanta 56(3), 383-393.

${ }_{350}$ Nilchi, A., Saberi, R., Moradi, M., Azizpour, H. and Zarghami, R. (2011) Adsorption of cesium on copper

${ }_{351}$ hexacyanoferrate-PAN composite ion exchanger from aqueous solution. Chemical Engineering Journal 352 172(1), 572-580.

${ }_{353}$ Parab, H. and Sudersanan, M. (2010) Engineering a lignocellulosic biosorbent - Coir pith for removal of cesium from 354 aqueous solutions: Equilibrium and kinetic studies. Water Research 44(3), 854-860. 
${ }_{355}$ Plazinski, W. and Rudzinski, W. (2009) Modeling the Effect of Surface Heterogeneity in Equilibrium of Heavy Metal 356 Ion Biosorption by Using the Ion Exchange Model. Environmental Science \& Technology 43(19), $357 \quad 7465-7471$.

${ }_{358}$ Pyrasch, M., Toutianoush, A., Jin, W.Q., Schnepf, J. and Tieke, B. (2003) Self-assembled films of Prussian blue and 359 analogues: Optical and electrochemical properties and application as ion-sieving membranes. Chemistry of $360 \quad$ Materials 15(1), 245-254.

${ }_{361}$ Ramaswamy, M. (1999) Synthesis, Sorption and Kinetic Characteristics of Silica-Hexacyanoferrate Composites. $362 \quad$ Solvent Extraction and Ion Exchange 17(6), 1603-1618.

${ }_{363}$ Reddad, Z., Gerente, C., Andres, Y. and Le Cloirec, P. (2002) Adsorption of Several Metal Ions onto a Low-Cost 364 Biosorbent: Kinetic and Equilibrium Studies. Environmental Science \& Technology 36(9), 2067 -2073. ${ }_{365}$ Saadat, S. and Karimi-Jashni, A. (2011) Optimization of Pb(II) adsorption onto modified walnut shells using factorial $366 \quad$ design and simplex methodologies. Chemical Engineering Journal 173(3), 743-749.

${ }_{367}$ Tsai, S.-C., Wang, T.-H., Li, M.-H., Wei, Y.-Y. and Teng, S.-P. (2009) Cesium adsorption and distribution onto 368 crushed granite under different physicochemical conditions. Journal of Hazardous materials 161(2-3), $369 \quad 854-861$.

${ }_{370}$ Volchek, K., Miah, M.Y., Kuang, W., DeMaleki, Z. and Tezel, F.H. (2011) Adsorption of cesium on cement mortar 371 from aqueous solutions. Journal of Hazardous materials 194(0), 331-337.

${ }_{372}$ Zabihi, M., Haghighi Asl, A. and Ahmadpour, A. (2010) Studies on adsorption of mercury from aqueous solution on 373 activated carbons prepared from walnut shell. Journal of Hazardous materials 174(1-3), 251-256. 
Graphic abstract:

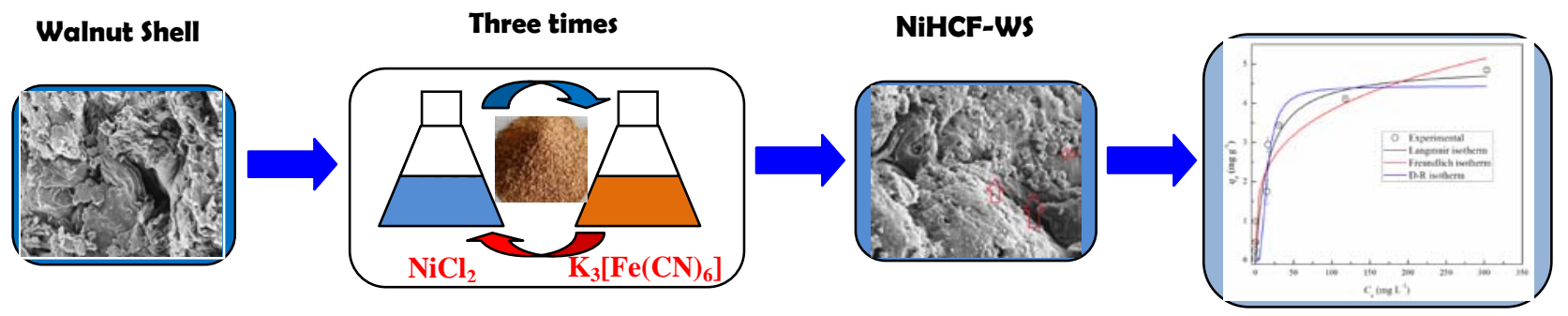




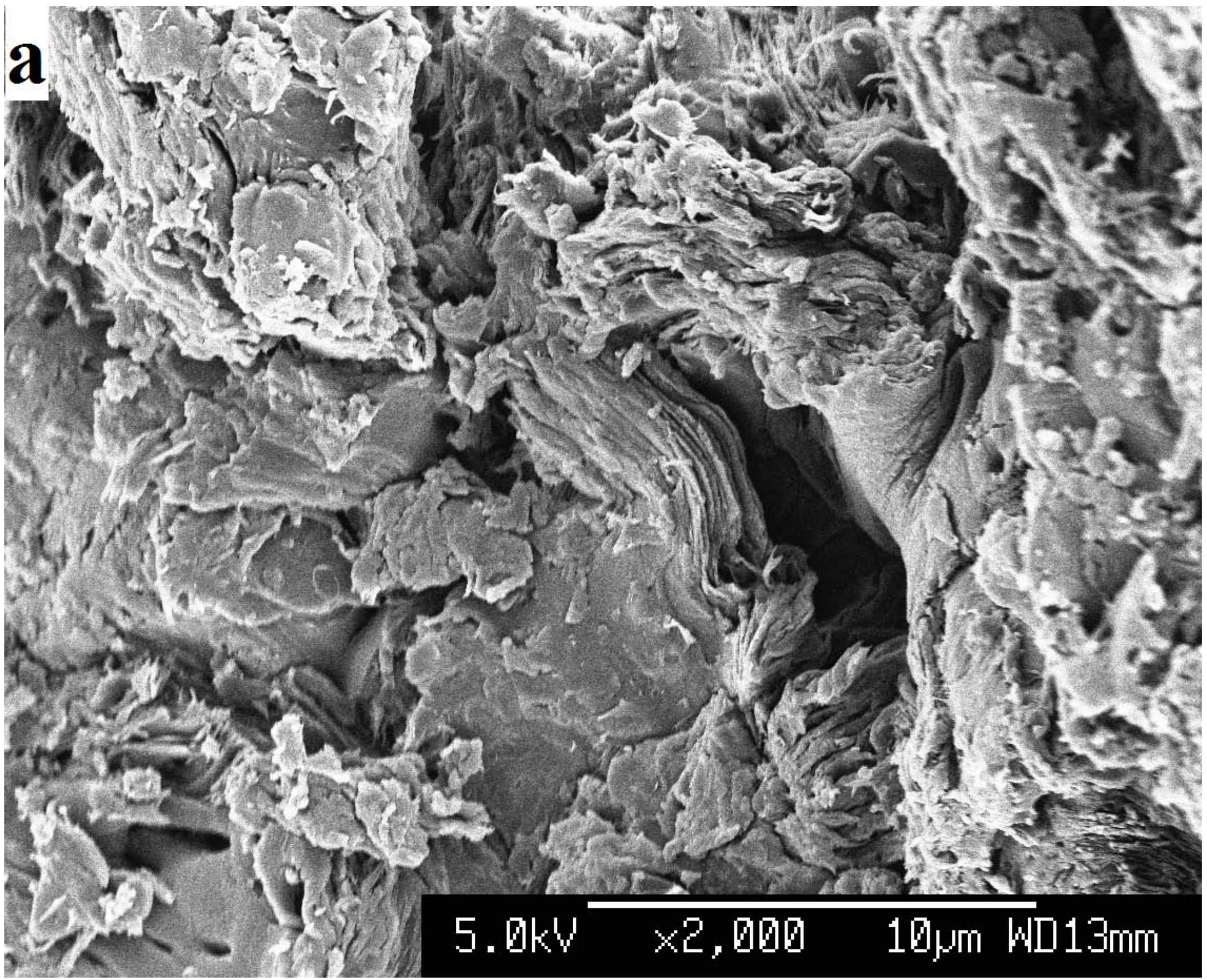




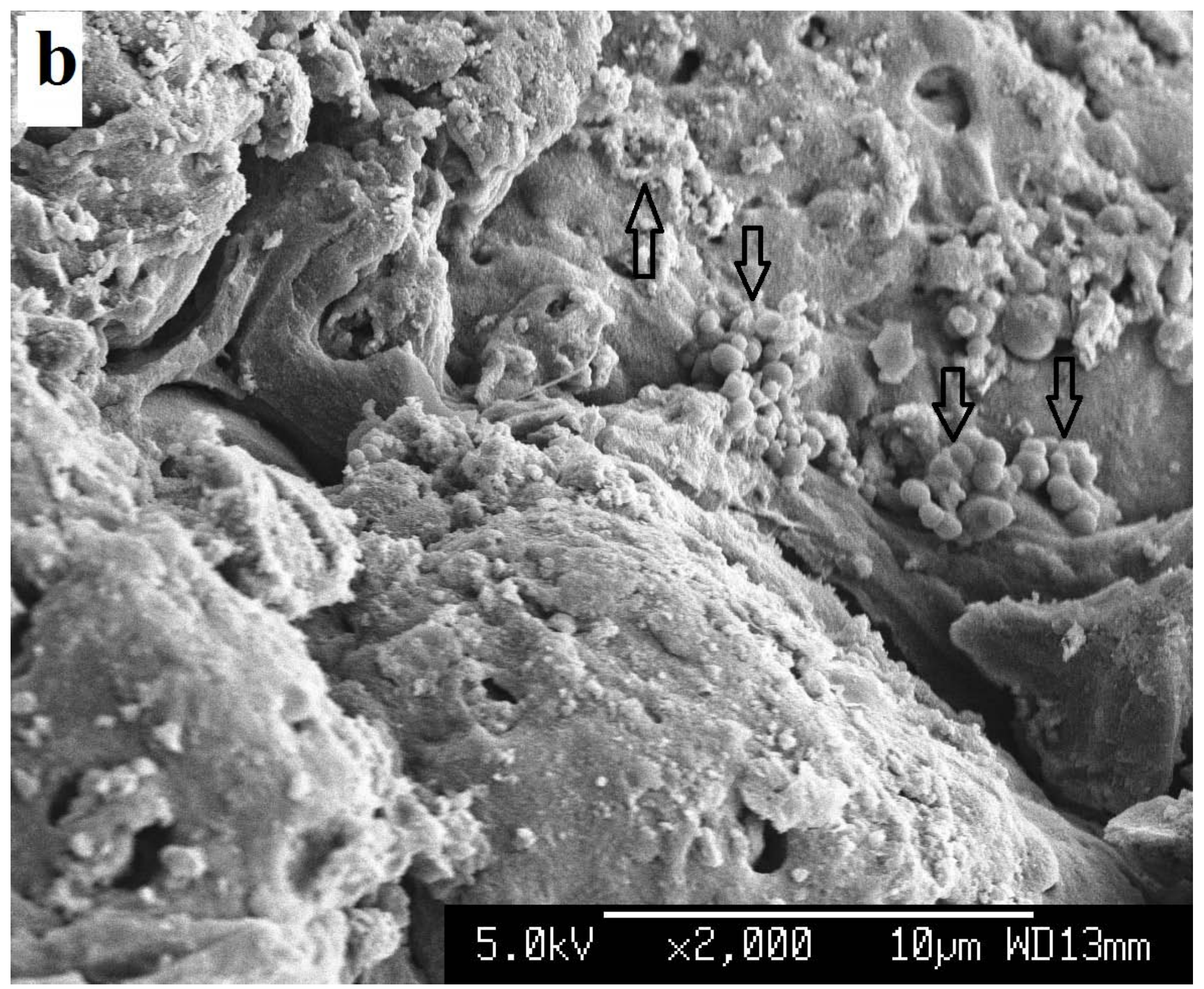




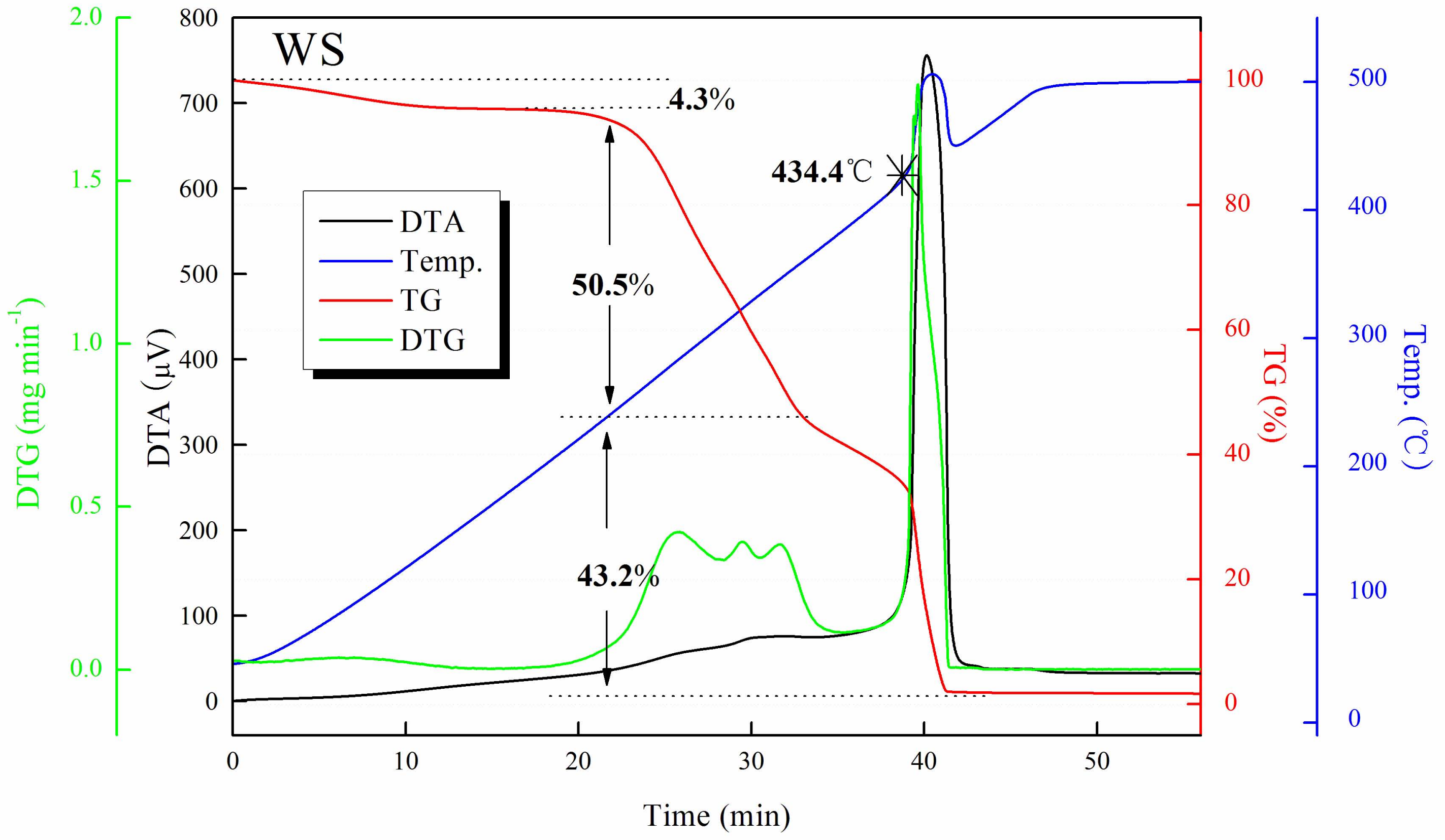




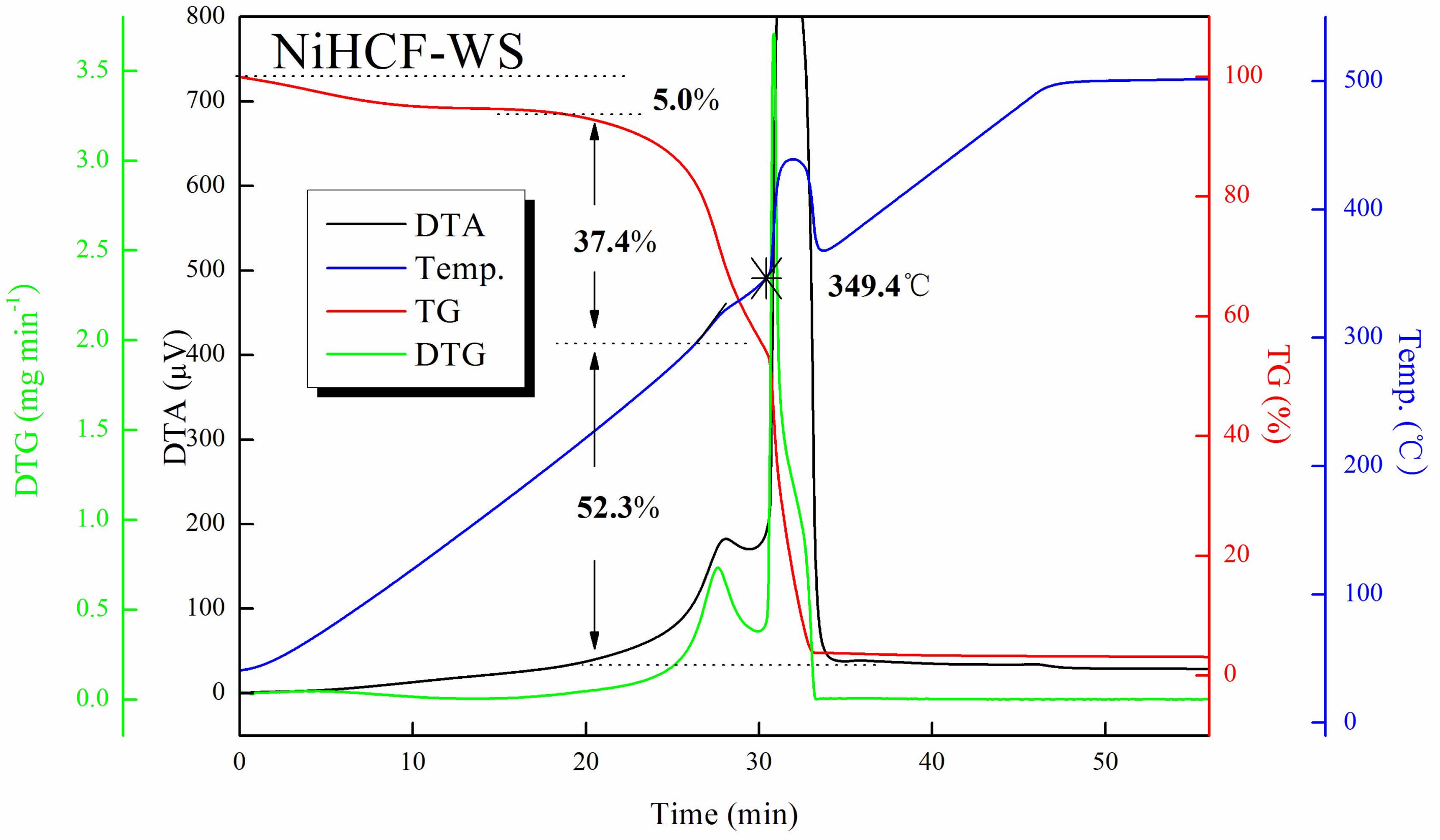



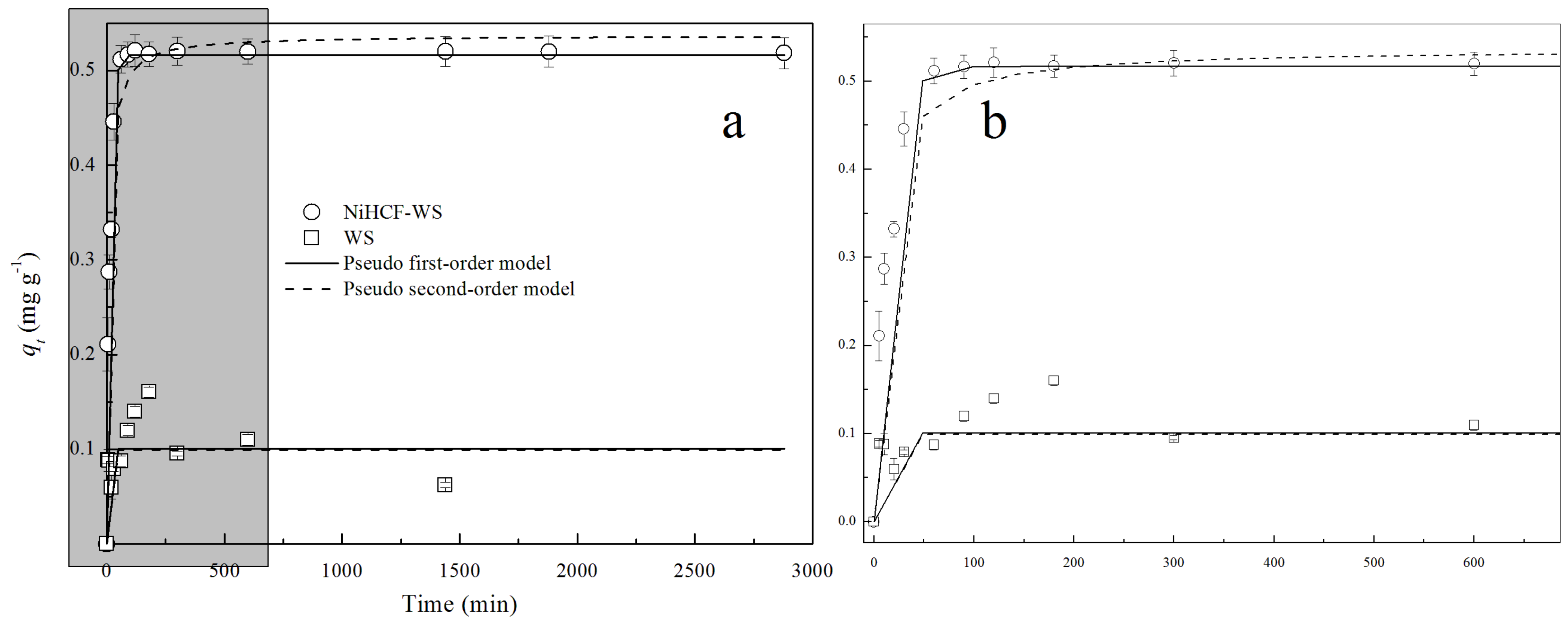
Fig. 5

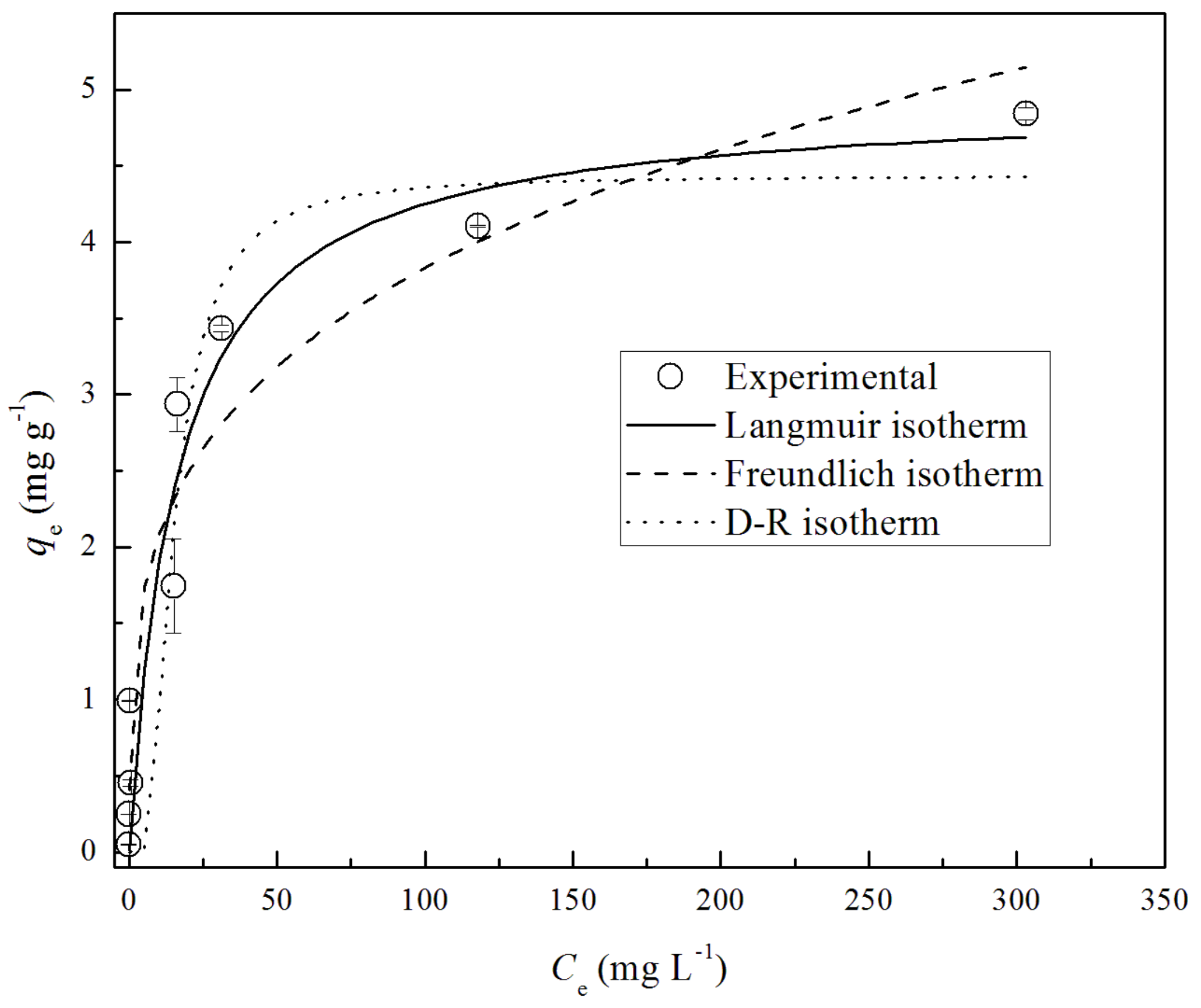




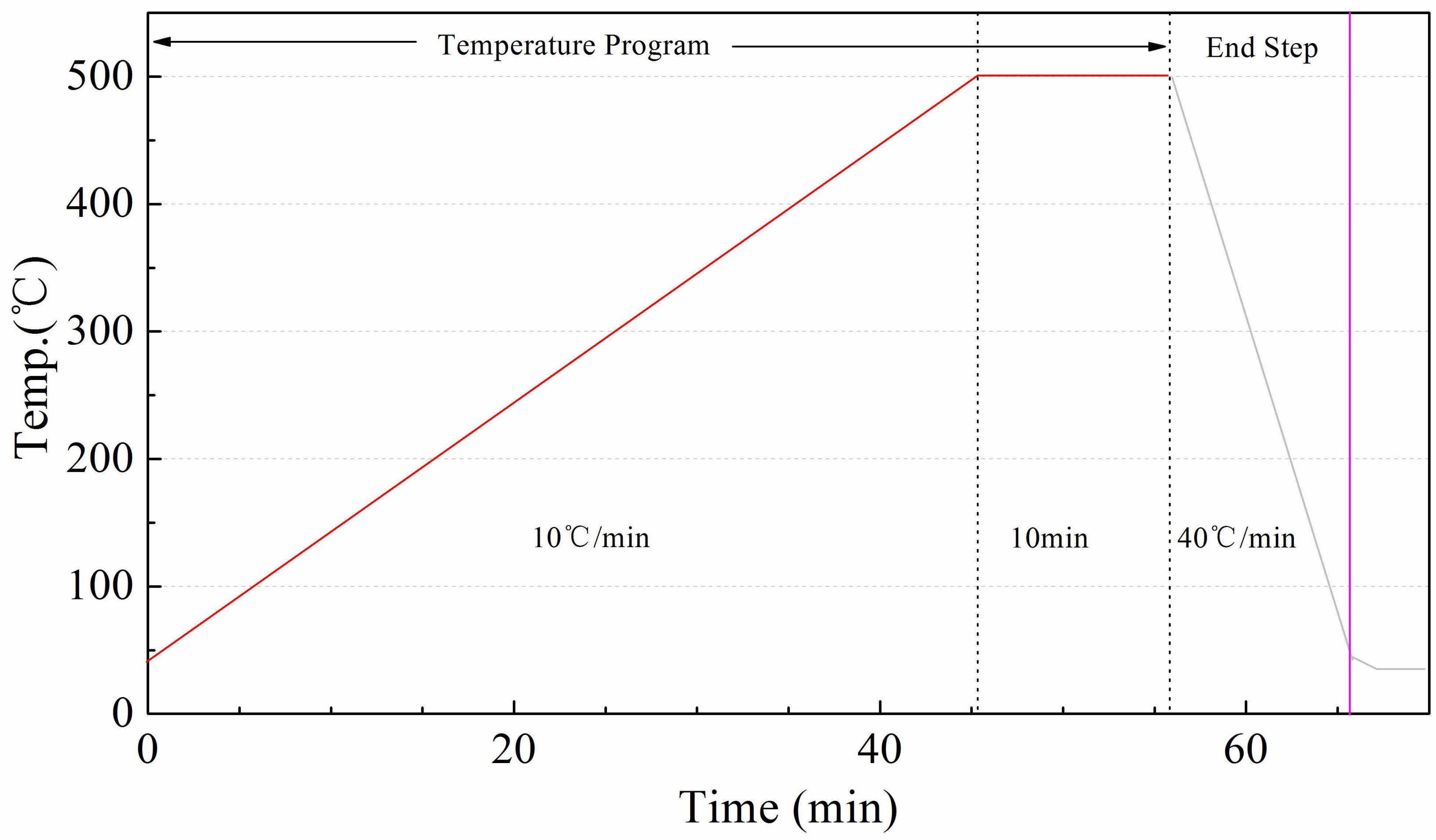


Fig. S2

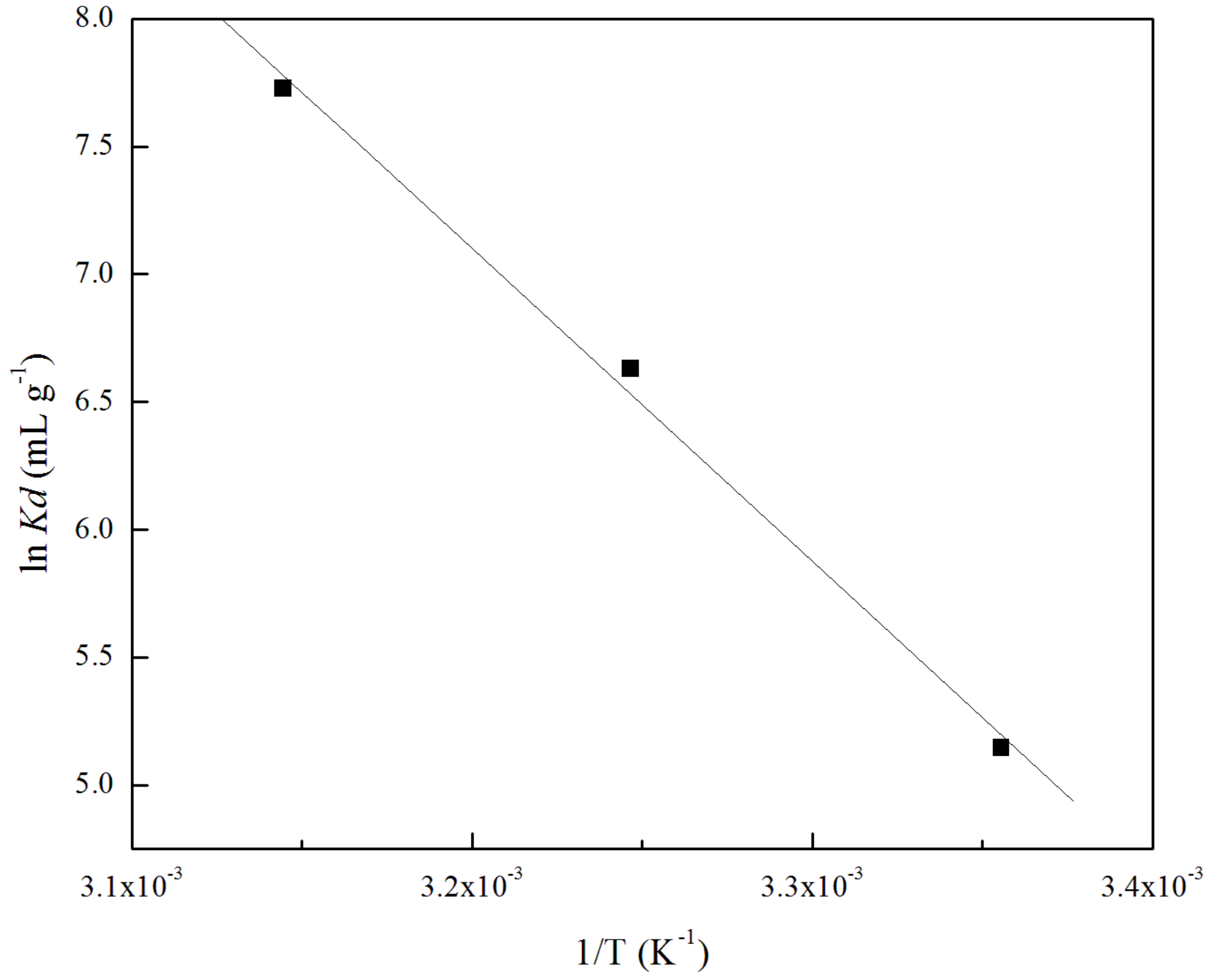




\section{Figure captions:}

Fig.1 - Typical scanning electron microscope images of walnut shell before (a) and after (b) modification. (Acceleration voltage of 5.0kV and 2000× magnification, arrows show the nickel hexacyanoferrate particles)

Fig.2 - TG-DTA results of walnut shell and nickel hexacyanoferrate incorporated walnut shell obtained at the heating rate of $10^{\circ} \mathrm{C} \min ^{-1}$ in air atmosphere. (Pan: Al-Pan; Reference: Open-Al-Pan; Upper limit temperature: $550^{\circ} \mathrm{G}$, Gas flow rate: $200 \mathrm{~mL} \mathrm{~min}^{-1}$ )

Fig.3 - Application of non-linearized pseudo first (solid line) and second (dash line) order kinetic models for cesium (10mg L $\mathrm{L}^{-1}$ ) adsorption by walnut shell (square) and nickel hexacyanoferrate incorporated walnut shell (circle) at $25^{\circ} \mathrm{C}\left(20 \mathrm{~g} \mathrm{~L}^{-1}\right)$. (Fig.(b) shows the enlarged dark part in Fig.(a).)

Fig.4 - Intra-particle diffusion model of cesium $\left(10 \mathrm{mg} \mathrm{L}^{-1}\right)$ adsorption by nickel hexacyanoferrate incorporated walnut shell $\left(20 \mathrm{~g} \mathrm{~L}^{-1}\right)$ at $25^{\circ} \mathrm{C}$ (Symbols represent the experimental data.)

Fig.5 - Nonlinear Langmuir (solid line), Freundlich (dash line) and D-R (dot line) isotherms of cesium adsorption on nickel hexacyanoferrate incorporated walnut shell at $25^{\circ} \mathrm{C}$. (Symbols represent the experimental data, whereas the lines represent the simulated data fitted using the adsorption isotherms.) 
Fig. S1 - Temperature program of TG-DTA analysis. (Red line represents the temperature program and only during this period the experimental data are recorded. Gray line shows the end step with a speed of $40^{\circ} \mathrm{C} \mathrm{min}^{-1}$ and as said, the experimental data are not recorded during this step.)

Fig. S2 - Effect of solution temperature on the distribution coefficient of cesium $\left(10 \mathrm{mg} \mathrm{L}^{-1}\right)$ adsorption by NiHCF-WS $\left(10 \mathrm{~g} \mathrm{~L}^{-1}\right)\left(\mathrm{R}^{2}=0.99\right)$. 
Table 1

Pseudo first-order kinetic model

\begin{tabular}{|c|c|c|c|c|c|}
\hline & WS & NiHCF-WS & & WS & NiHCF-WS \\
\hline $\mathrm{q}_{\operatorname{eexp}}{ }^{\mathrm{a}}\left(\mathrm{mg} \mathrm{g}^{-1}\right)$ & $0.11 \pm 0.04$ & $0.52 \pm 0.004$ & $\mathrm{q}_{\text {eexp }}\left(\mathrm{mg} \mathrm{g}^{-1}\right)$ & $0.11 \pm 0.04$ & $0.52 \pm 0.004$ \\
\hline $\mathrm{k}_{1}\left(\min ^{-1}\right)$ & $0.37 \pm 0.39$ & $0.071 \pm 0.006$ & $\mathrm{k}_{2}\left(\mathrm{~g} \mathrm{mg}^{-1} \min ^{-1}\right)$ & $(-3.8 \pm 4.0) \times 10^{45}$ & $0.23 \pm 0.03$ \\
\hline $\mathrm{q}_{\text {ecal }}{ }^{\mathrm{b}}\left(\mathrm{mg} \mathrm{g}^{-1}\right)$ & $0.10 \pm 0.01$ & $0.52 \pm 0.009$ & $\mathrm{q}_{\mathrm{ecal}}\left(\mathrm{mg} \mathrm{g}^{-1}\right)$ & $0.099 \pm 0.01$ & $0.54 \pm 0.01$ \\
\hline $\mathrm{R}^{2}$ & 0.492 & 0.946 & $\mathrm{R}^{2}$ & 0.483 & 0.981 \\
\hline
\end{tabular}

${ }^{a}$ means the equilibrium sorption capacity estimated from the experimental data.

${ }^{\mathrm{b}}$ means the equilibrium sorption capacity calculated from the kinetic model. 
Table 2

\begin{tabular}{|c|c|c|c|c|c|}
\hline \multicolumn{2}{|c|}{ Langmuir isotherm } & \multicolumn{2}{|c|}{ Freundlich isotherm } & \multicolumn{2}{|c|}{$\mathrm{D}-\mathrm{R}$ isotherm } \\
\hline $\mathrm{q}_{\mathrm{m}}\left(\mathrm{mg} \mathrm{g}^{-1}\right)$ & $4.94 \pm 0.5$ & $\mathrm{k}_{\mathrm{f}}\left(\mathrm{mg} \mathrm{g}^{-1} \mathrm{~L}^{1 / \mathrm{n}} \mathrm{mg}^{-1 / n}\right)$ & $1.12 \pm 0.2$ & $\overline{q_{m}\left(m g ~ g^{-1}\right)}$ & $4.43 \pm 0.4$ \\
\hline $\mathrm{b}\left(\mathrm{L} \mathrm{mg}^{-1}\right)$ & $0.06 \pm 0.02$ & $\mathrm{n}$ & $0.27 \pm 0.04$ & $\beta\left(\mathrm{mol}^{2} / \mathrm{kJ}^{2}\right)$ & $(3 \pm 0.8) \times 10^{-5}$ \\
\hline $\mathrm{R}^{2}$ & 0.93 & $\mathrm{R}^{2}$ & 0.93 & $\mathrm{R}^{2}$ & 0.92 \\
\hline$\chi^{2}$ & 21.1 & $\chi^{2}$ & 0.96 & $\chi^{2}$ & $1.3 \times 10^{281}$ \\
\hline NSD (\%) & 57.3 & NSD (\%) & 60.7 & NSD (\%) & 310.2 \\
\hline
\end{tabular}


Table $3^{\text {a }}$

\begin{tabular}{lcccc}
\hline No. & $\begin{array}{c}\text { Dosage } \\
\left(\mathrm{g} \mathrm{L}^{-1}\right)\end{array}$ & $\begin{array}{c}\text { Initial } \mathrm{Cs}^{+} \text {concentration } \\
\left(\mathrm{mg} \mathrm{L}^{-1}\right)\end{array}$ & $\begin{array}{c}\mathrm{Cs}^{+} \text {adsorbed } \\
(\mu \mathrm{mol})\end{array}$ & $\begin{array}{c}\mathrm{K}^{+} \text {released } \\
(\mu \mathrm{mol})\end{array}$ \\
\hline 1 & 5 & 10 & $0.5 \pm 0.02$ & $0.1 \pm 0.0$ \\
2 & 10 & 10 & $0.9 \pm 0.002$ & $1.5 \pm 0.06$ \\
3 & 15 & 10 & $1.4 \pm 0.001$ & $4.6 \pm 0.3$ \\
4 & 20 & 10 & $1.4 \pm 0.001$ & $4.7 \pm 0.2$ \\
5 & 20 & 100 & $10.3 \pm 0.07$ & $13.4 \pm 0.2$ \\
6 & 20 & 200 & $12.3 \pm 0.01$ & $16.7 \pm 0.02$ \\
7 & 20 & 400 & $14.6 \pm 0.1$ & $19.6 \pm 0.1$ \\
\hline
\end{tabular}

${ }^{\text {a }}$ Samples were tested in $50 \mathrm{~mL}$ polypropylene tubes with $20 \mathrm{~mL} \mathrm{Cs}^{+}$solutions at room temperature and 200rpm for 24h. 
Table 4

\begin{tabular}{lcccc}
\hline Temp. (K) & $K d\left(\mathrm{~mL} \mathrm{~g}^{-1}\right)$ & $\Delta \mathrm{G}^{\circ}\left(\mathrm{kJ} \mathrm{mol}^{-1}\right)$ & $\Delta \mathrm{H}^{\circ}\left(\mathrm{kJ} \mathrm{mol}^{-1}\right)$ & $\Delta \mathrm{S}^{\circ}\left(\mathrm{kJ} \mathrm{K}^{-1} \mathrm{~mol}^{-1}\right)$ \\
\hline 298 & 171.4 & -12.9 & & \\
308 & 757.1 & -16.8 & 101.8 & 0.385 \\
318 & 2264.3 & -20.6 & & \\
\hline
\end{tabular}

